\title{
Deneysel Kolaj Uygulamalarının Temel Tasarım Elemanları ile Incelenmesi
}

\author{
Examining Experimental Collage Applications with Basic Design Elements
}

\author{
Nurdan Kumaş Şenol ${ }^{*}$ (1), Ali Osman Elmas ${ }^{* *}$ (1)
}

Öz

Kolaj, hâlihazırda var olan her türlü basılı, fotoğrafik veya çizim hâlinde bulunan malzemenin herhangi bir yüzeyin üzerine yeni bir tasarım oluşturacak şekilde yapıştırılmasıyla elde edilir. Kolajın yapı malzemesi ne olursa olsun, izleyicide gerçeklik duygusunu yaratmak için oluşturulan kurmaca gerçeklik ön plandadır. 20. yüzyıl sanatında ilk defa kübistler tarafından bulunan kolaj, dadaistler tarafından geliştirilmiş bir görsel sanatlar tekniği olarak tanımlanmaktadır. Kübistler modern sanatın bu yeni akımını gerçek nesnelerle kullanarak, sanat eserlerinin ulaştığı otonom derecesini de işaret etmişlerdir. Dadaistler ise tasviri reddederek nesnelerin salt kendilerini temsil etmek isteyen anlayışı benimsemişlerdir. Asamblaj, montaj ve fotomontaj kavramlarını içinde bulunduran kolaj tekniklerinin özüne gündelik malzemelerin de dâhil edilmesiyle birlikte kolaj, bilinen anlamından farklı bir boyuta taşınmıştır. Kolajın konstrüksiyonu gereği, sanatsal uygulamalardaki spekülatif çeşitliliğe kreatif çözümler üretmede zengin anlatım olanaklarını içerdiğine ilişkin örnekleri çoğaltmak mümkün olsa da önemli olan sanatsal kurguya can verecek özgün ve yaratıcı bir düşünceye ulaşmaktır. Özellikle görsel sanatlara yüklenen bu anlama sürecinde ortaya çıkan üretme ve yorumlama becerisi temel tasarım elemanları ile ayrı bir değer taşır. Literatür açısından ele alındığında, uygulamanın konu bağlamında nispeten az işlenmiş ve yetersiz sayılabilecek örnekleri olduğundan konunun temel tasarım öğeleri açısından incelenmesi uygun görülmüştür. Bu açıdan da kolaj tekniğinin işlevselliği, kavramları ve temel tasarım elemanları açıklanmış; bulgular ve yorum kısmında ise deneysel olarak tasarlanan özgün kolaj uygulamaları temel tasarım elemanları açısından incelenip yorumlanmıştır.

Anahtar Kelimeler

Kolaj, Kübizm, Dadaizm, Temel Tasarım Elemanları

\section{Abstract}

Collage is created by sticking any existing printed, photographic or drawing material onto any surface to create a novel design. Whatever the building material of the collage is, the fictional reality that creates the sense of reality in the audience is at the forefront. Collage, first practiced by Cubists in twentieth-century art, is defined as a visual art technique which was subsequently developed by Dadaists. By using this new trend of generating modern art with real objects, the Cubists also pointed out the degree of autonomy artworks have thereby achieved. Dadaists, on the other hand, refuse to depict, instead adopting the view that objects only want to represent themselves. The collage techniques, which include the concepts of assembly, montage and photomontage, have been movedto a different dimension from its known meaning with the use of everyday materials as its essence. Through the construction of the collage, although it is possible to

* Sorumlu Yazar: Nurdan Kumaş Şenol (Öğr. Gör.), Giresun Üniversitesi, Teknik Bilimler Meslek Yüksekokulu, Tasarım Bölümü, Giresun, Türkiye. E-posta: nurdan.senol@giresun.edu.tr ORCID: 0000-0002-1161-2665

** Ali Osman Elmas (Öğr. Gör.), Giresun Üniversitesi, Teknik Bilimler Meslek Yüksekokulu, Tasarım Bölümü, Giresun, Türkiye. E-posta: ali.elmas@giresun.edu.tr ORCID: 0000-0002-8626-3850

Atıf: Kumas-Senol, Nurdan ve Elmas, Ali Osman. "Deneysel Kolaj Uygulamalarının Temel Tasarım Elemanları ile İncelenmesi." Art-Sanat, 15(2021): 183-201. https://doi.org/10.26650/artsanat.2021.15.0008 
reproduce the examples showing that it includes rich expressive possibilities in producing creative solutions to the speculative diversity in artistic applications, the important thing is to reach an original and creative thought that will enliven the artistic fiction. The ability to produce and interpret, which arises in this comprehension process, especially emphasised in visual arts, carries a distinct value with its basic design elements. Considering the paradigm in terms of the literature, it was deemed appropriate to examine the subject in terms of basic art elements, as there are examples of the application that are relatively less processed in the context of the subject. In this respect, the functionality of the collage technique is delineated with its concepts and basic design elements. In the findings and interpretation section of the paper, the original collage applications designed experimentally were examined and interpreted in terms of the basic design elements.

Keywords

Collage, Cubism, Dada, Basic Design Elements

\section{Extended Summary}

A collage is obtained by constructing it on a surface with any printed, etched or photographic material to create a new composition. Thus, an artwork can be created by using various materials that are not artistic per se, as they are used only to create a composition by being cut, pasted, added, etc. The collage technique associated with actions means deconstructing and rebuilding in all artistic fields. In this constructive understanding, the collage artist is not interested the individual design elements-the artist finds the piece that will be useful in the design. The concept of collage can be evaluated in two contexts. The first is "paste," which refers to the technical construction of the collage and the dictionary meaning; the second is to bring together bakımından in terms of meaning. The action of sticking in collage is distinguished from other task elements in that it is not made simply for decoration purposes and does not include re-joining of broken pieces.

As art is a part of life, it has created its own visual language and rules in every period. This identity, created in every work of art, is fed by the "present" we are in. Cubists were willing to face the realities of the period and handled the objects with their known aspects. Dadaists have tried more aggressive ways in the artistic context rather than the context of the period. Thanks to these aggressive attitudes, they allowed their independent thoughts to emerge.

The Cubists, Futurists and Dada artists used collage according to their subject and style with using a variety of materials. Today, we see the collage technique in contemporary art in contemporary art formations such as Installation and Land art. It is used either as a reality or as a collage inserted into space.

Cubists who make real objects a part of their art; also inspired many trends of modern art. For this reason, collage was first used by Picasso and Braque as an artistic form in the period 1911-14 termed Synthetic (Combinational) Cubism. During this period, Picasso and Braque opened doors to a different understanding by sticking non-art objects such as linoleum, newspaper, and wallpaper on to the surfaces of their works. 
There are three concepts of collage technique. Assembly, packing and photomontage. Assembly is considered a form of behavior and artistic production seen in twentieth-century art. The artist who applied the assembly technique for the first time in the history of art was Picasso. As a result of his creativity in art, he brought the third dimension to the collage technique and produced the first examples of the assembly technique. Dada movement artists, who used the montage technique the most, have often included politics and political messages in their assemblies, unlike artists in other movements. The main material of the photomontage technique also provided the artists with a rich opportunity for expression with darkroom processes, color, texture, detail shots or using these techniques simultaneously.

Basic design elements ensure the creation of the desired and expected composition in the design process. A design is realized by using many elements and many principles together. What we describe as the basic design elements are divided into seven different branches; Line, Shape, Shape, Space, Color, Texture and Pattern. Line with an endless series of dots is an important tool in design. Thanks to this descriptive feature, it makes many contributions to the works. Lines contain various meanings depending on their location. Straight lines: while giving a feeling of simplicity, evoke strength and calm; Vertical lines: signify life, vitality and mobility; Horizontal lines give a sense of calm and death, while curved and spiral lines give a sense of energy and dynamism. In the historical process, it is seen that the line affected many artists and designers and the effect continued in every period. Picasso, Matisse, Pollock and Klee exemplify leading artists influenced by the power of the line. The shapes themselves, shapes in various features and designs give the space different effects. The use of shapes with different methods allows us to obtain novel and different shapes. The format in basic design literature allows us to perceive design elements in three dimensions. With the form element that allows us to express objects, works with aesthetic integrity are also obtained in terms of function. The spacer element, also defined as space, is the space between forms. It is possible to obtain the most accurate effect in a composition through the spaces that separate the object from the environment and make sense according to its function. Color is technically the wavelength of light that the human eye can see, and color acts as a powerful visual tool. Color harmony in any kind of work and production, where color is used as a basic language, gives a sense of order and inspires visual curiosity. Therefore, designers add aesthetic beauty to their designs with this design element. The texture has a three-dimensional structure. Detailed information about the internal and external structure of the object can only be accessed thanks to the texture. Pattern (Direction) is any visible edge of a surface. In two-dimensional designs, the pattern is presented with light and shadow, while the three-dimensional form gains volume. There are generally three main directions: vertical, horizontal and diagonal. 
After the literature review of the study has been completed, the application section follows. In this section, which includes experimental collage studies, interpretations are made about each of the works created with basic design elements.

As a result, no matter what material is used in the production process of the collage, the feeling that it sets out to impress the audience has become a reality. Thanks to this effect, the language of reality has been shaped with a rich infrastructure. It has been concluded that this branch of art, which broadens the perspective of the designers, will enhance the value and originality of their designs that have their own interpretation power. 


\section{Giriş}

Temel tasarım elemanlarının etkin bir biçimde kullanılması tasarım süreci açısından vazgeçilmez bir gerekliliktir. Gözlem ve üretim ortamında ele alınan konular, belirli bir uyum içerisinde bu süreçte etkileşime girmektedir. Yeniden üretim, sanatsal yaratıda geçmişten bu yana sanrılı bir süreç içerisinde olmuştur. Bu nedenle sanatçılar tasarım süreçlerine yenilik getirerek düzensiz parçaları tasarım elemanlarını oluşturan nokta, çizgi, düzlem-hacim, biçim-form, aralık, doku, yön ve renk öğeleri girift bir şekilde kullanmaya başlamıştır. Bununla birlikte hem temel tasarım elemanları daha hızlı kavranmış hem de ifade çeşitliliği kolaj tekniği ile birlikte kullanılarak yaratım süreci belirli bir düzen ve ahenk içinde oluşturulmuştur.

\section{Görsel Sanatlarda "Kolaj”}

Kolaj; Fransızca coller sözcüğünden türetilen bir kelime olup bir araya getirme, birleştirme, yapıştırma anlamına gelmektedir ${ }^{1}$. Bir başka ifadeyle bir resmin bünyesine uygun olarak yapıştırılan çeşitli kâğıt parçaları ya da buna benzer gereçlerle yapılan eserdir ${ }^{2}$. Kolaj elde mevcut olan her türlü basılı, çizili ya da fotoğrafik malzemenin bir yüzey üzerine yeni bir kompozisyon oluşturacak düzende yapıştırılmasıyla elde edilmektedir. Böylelikle kendileri sanatsal nitelikte olmayan çeşitli malzemeler, yalnızca bir kompozisyon oluşturmak için kullanılmaları sayesinde bir sanat eseri meydana getirilebilmektedir ${ }^{3}$. Ayrıca bu yöntem aracılığıyla tek başlarına sanatsal içerik ve nitelikte olmayan imajlar, yeni bir anlamı doğuracak ya da daha önceden üretilmiş anlamı yadsıyacak biçimde düzenlenerek, sanat eserini oluşturan elemanlar hâline gelirler ${ }^{4}$. Kesme, yapıştırma, ekleme vb. eylemlerle ilişkilendirilen kolaj tekniği, tüm sanatsal alanlarda yıkma ve yeniden inşa etme anlamına gelir. Kolaj sanatçısı bu inşacı anlayış içinde parçaların bütünüyle ilgilenmez, tasarımında kendine yarayacak olan parçayı bulur. Kesme, parçalama, yıkma eylemleri bir kolaycılık olarak görülse de kolaj bu aşamada bırakılmayacağı için yeniden kurma, yapma ve birleştirme işlemleriyle tamamlanan süreç sonunda, öznenin kendini bulması, var etmesi ve güveniyle sonuçlanır ${ }^{5}$. Kolaj kağıtla sınırlı değildir. Sonsuz sayıda kolaj materyalleri vardır. Burada anahtar nokta, kalite ve düzenlemedir ${ }^{6}$.

Kolaj kavramı iki bağlamda değerlendirilebilir: Birincisi kolajın teknik olarak yapılışını ve sözlük anlamını ifade eden yapıştırma; ikincisi ise anlam bakımından bir

1 Richard Hamilton, Kolaj (İstanbul: Boyut Yayın Grubu, 2013), 28.

2 Adnan Turani, Dünya Sanat Tarihi (İstanbul: Remzi Kitabevi, 1995), 78.

3 Metin Sözen ve Uğur Tanyeli, Sanat Kavramı ve Terimleri Sözlüğü (İstanbul: Remzi Kitabevi, 2005), 137.

4 Cemil Ergün, “Temel Sanat Eğitiminde ve Çağdaş Sanatta Kolaj- Fotomontaj," Sanat ve Tasarım Dergisi 1 (2014), 5-19.

5 Mustafa Durak, "Kolaj Tarihine Giriş”, erişim 24 Nisan 2020, https://tr.scribd.com/document/23283244/ kolaj- tarihinegiriş-introduct

6 Jill Englebright Fox and Robert Schirrmacher, Çocuklarda Sanat ve Yaratıcılı̆̆ın Gelişimi, çev. Neriman Aral, Gökhan Duman (Ankara: Nobel Yayınları, 2012), 179. 
araya getirmedir. Kolajda yapıştırma eylemi süsleme amaçlı yapılmaması ve kopmuş parçaların tekrar bitiştirilmesini içermemesi yönüyle diğer yapıştırmalardan ayrılır. Süslemeye dayalı birçok geleneksel teknik ve uygulama her ne kadar eylem olarak benzerlik gösterse de anlam olarak kolajdan farklıdır?

Sanat, hayatın bir parçası olması sebebiyle kendi görsel dilini ve kurallarını her dönemde oluşturmuştur. Kübistler ve Dadacılar, kolajı kurallı ya da kuralsız malzemenin değişimiyle kendi konu ve üslubuna göre kullanmışlardır. Bugün kolaj tekniğini enstelasyon, landart gibi güncel sanat oluşumlarının içinde görmekteyiz. Tüketimin artıklarını olduğu kadar üretimin çokluklarını da bir araya getiren kolaj modernizmin perspektifinden bakıldığında sanatın sanatla olan mücadele alanıdır. Sanat tarihi, sanat için henüz kazak örmeye soyunmuşken aynı yıllarda kolaj yakaladığı ilmeklerden o kazağı sökmeye başlamıştır. Bu sebeple kolaj sanatın sadece estetikle değil, kendisinin varlık koşullarını sorgulamasıyla da ilgilidir. Onun sınırları modernizmin sınırlarıdır. Dolayısıyla geç-modernite çağında kolajı düşünmek nereden bakılsa gecikmiş bir düşüncedir. Belki de sadece bu yüzden yeni bir anlamı işaret edebilir"».

Aragon'un da dediği gibi kolaj, "tekniğin reddini içerir". Kolaj, yüzyıl tarihi boyunca birçok karşı kültür akımının sözcüsü olmuştur. Minimalismin antiform anlayışı ve ardından gelişen Kavramsal Sanat'ın da etkisiyle içeriğin ifadesinin biçimin önüne geçmesi ve baskı yöntemlerinin gelişmesi; modernist sanatsal estetikten çok, politik mesajın reklam dilini kullanarak verildiği politik bir sanatın doğuşuna da zemin hazırlamıştır9.

Kolaj ilk defa sanatsal bir form düzeyinde 1911-1914 arasındaki Sentetik (Birleşimsel) Kübizm olarak adlandırılan dönemde Picasso ve Braque tarafından kullanılmıştır. $\mathrm{Bu}$ dönemde Picasso ve Braque yaptıkları çalışmaların yüzeylerine muşamba, gazete, duvar kağıdı gibi sanat dışı nesneler yapıştırarak farklı bir anlayışa kapı aralamışlar$\operatorname{dir}^{10}$ (G. 1).

7 Kardelen Kılıç, “2000’li yıllarda Türkiye'de Kolaj: Sanatçılar ve Uygulamaları” (Yüksek Lisans Tezi, Uludağ Üniversitesi, 2019), 6.

8 Sedef Acar, “Jack Lenor Larsen: İç Mekân Tekstili Tasarımında Bir Öncü,” İnönü Üniversitesi Sanat ve Tasarım Dergisi, 7 (2013): 81-91.

9 Betül Karakaya ve Menekşe Eda Öztürmen, "Porselen Bibloda Kolaj ve Asamblaj," International Journal of Interdisciplinary and Intercultural Art 4 (2019), 24.

10 A. C. Krausse, Rönesans 'tan Günümüze Resim Sanatının Öyküsü, çev. Dilek Zaptcıŏlu (İstanbul: Literatür Yayinc1lik, 2005), 94. 


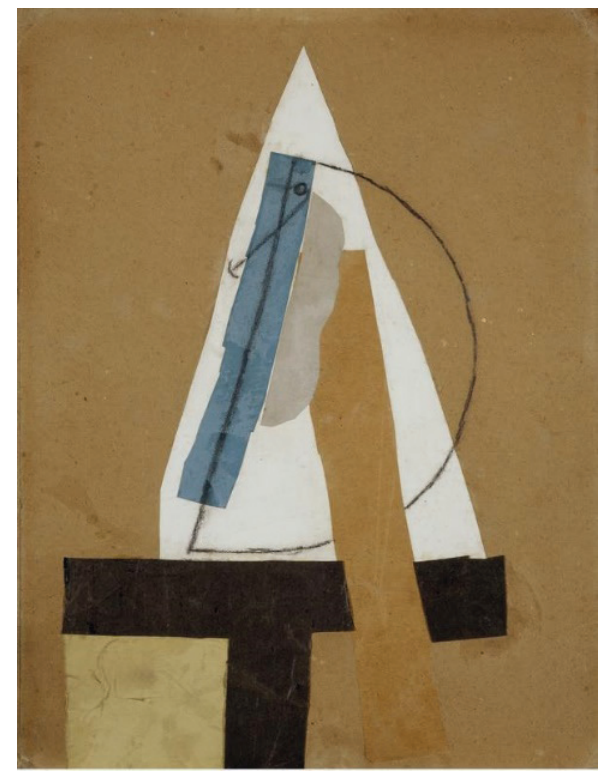

G. 1: Pablo Picasso, Tête (Head), Scottish National Gallery of Modern Art, 1913

Kehnemuyi, kolaj tekniğinin gerekliliğini şu şekilde belirtmiştir:

\begin{abstract}
“Günümüzde görüntüye bağlı anlatımların en şaşırtıcı değişken biçimselliği biriktirme ve yapıştırma sanatı olmuştur. Dadacılık ve Gerçeküstücülük mirasçıları olan biriktirme ve yapıştırma sanatının öfkeli genç kuşağı, çağın kalıntıları ve istenilmeyen atılmış şeylerin içine dalarak, kişiyi ve sanat eleştiricisini kızdıran, şaşırtan ve isyan ettiren bu tür plastik sanatı ortaya koymuştur. Alışılmış yağlıboya resimlerin yanı sıra kolaj tekniğini ilk uygulayan Pablo Picasso, Georges Braques, Juan Gris ve Hans Arp yıkıcı ve sert eleştirilere uğramışlardı. Öğretmenin bu tür sanatı ve sanatçıyı çocuğa sevdirip tanıtması çağ içi bir eğitim gereğidir"'11.
\end{abstract}

Günlük hayatta ve çevremizde olan çoğu nesne, kolaj tekniğinin bir parçası olarak yeniden yorumlanabilmektedir. Lynton, bu durumu şöyle açıklamıştır: Kolâjın birçok bakımdan sanatçıya büyük bir özgürlük kazandırdığı apaçık ortadadır. Sanatın göreneksel dağarcığının dışından ya da daha değersiz sayabileceğimiz bir kesimden malzeme kullanmak; gerçeklikle daha ülküleştirilmiş bir güzellik elde etmek için değil de oyun oynamış olmak için oynamak; aynı resimde birbiriyle çelişen bilgiler vermek; yapıştırma tekniği olan kolajdan yararlanarak her türlü resimsel dili hiçe saymak; resmin yüzeyini, içinden düşsel bir boşluğa bakılan bir pencere olarak kabul eden göreneksel anlayışı tümüyle yadsımak gibi ${ }^{12}$.

11 Aylin Beyoğlu, "Sanat Eğitiminde Kolaj Tekniği ve Richard Hamilton'ın Eser Örneğinin İncelenmesi”, Ege Eğitim Dergisi 16/2 (2015), 5.

12 Norbert Lynton, Modern Sanatın Öyküsü, çev. Cevat Çapan ve Sadi Öziş (İstanbul: Remzi Kitabevi 2004), 64. 


\section{Temel Tasarım Elemanları}

"Temel tasarım elemanları, tasarım sürecinde temel tasarım ilkeleri aracılığ 1 ile istenen ve beklenen kompozisyonun oluşturulmasını sağlarlar. Bir tasarım birçok eleman ve birçok ilkenin bir arada kullanılması ile gerçekleştirilmektedir. Ancak kullanılan elemanlar çoğunlukla eşdeğer değildir ve kompozisyonda biri ya da birkaçı öne çıkabilir"'3.

Görsel ifadenin temel elemanlarının ilki olan nokta; düzensizliğin içindeki ilk düzen elemanıdır. Geometrik olarak görselliğin anlatımında çeşitli büyüklüklerde boş ya da dolu yuvarlaklar olarak değerlendirilirr ${ }^{14}$. Biçim dağarcığının ana elemanı olan nokta;

- Bir çizginin iki ucunu,

- İki çizginin kesişimini,

- Bir düzlem ya da hacmin köşesindeki iki çizginin buluşmasını,

- Bir alanın merkezini belirlemeye yardımcı olan bir eleman olarak tanımlanmaktadır ${ }^{15}$.

Sanatta nokta; denge, hareketi durdurma, gözü belli odaklara çekme, plan etkisi yaratma, renk yüzeylerini benekler hâlinde zenginleştirme unsuru olarak kullanıldığ gibi optik yanılsamalara ve dekoratif anlatımlara da sinırsız olanaklar vermektedir ${ }^{16}$. Ayrıca bu sınırsız anlatım, nesnel tanımı ile yeri imgeleyen bir iz olarak nitelendirilebilir. Aralıkları eşit şekilde kullanılan noktalar, büyük-küçük, açık-koyu, dağınıkdüzenli gibi farklılıklar yeni bir yüzey oluşturmada etkinlik sağlar.

Çizgi, "basit bir anlatımla iki nokta arasındaki hat olarak tanımlanabilir. Resim ça1ışmasının temelini oluşturan çizgi aynı zamanda görsel bir anlatım aracıdır"'17. Sonsuz noktalar serisi olan çizgi; tasarımda önemli bir araçtır. Çizgi yaratıcı gücümüzün, teknik yeteneğimizin, hayal gücümüzün en kısa yoldan ifade edilmesini sağlar ${ }^{18}$. Hareket hâlindeki bir noktanın belirli bir yöndeki eğimi çizgiyi oluşturur'19. Çizgi ayrıca "hareket eden bir sivri ucun bir yüzey üzerinde bıraktığı aralıksız iz" olarak da tanımlanır ${ }^{20}$.

Kavramsal olarak düzlem, uzunluk ve genişlik içerir ancak derinliği yoktur. Düzlemin yüzey özellikleri, rengi, dokusu ve görsel etkisi kompozisyon açısından önemlidir. Bir kompozisyonda her bir düzlemin nitelikleri, tanımladıkları hacmin görsel ve çevre özelliklerini belirlemektedir ${ }^{21}$.

13 Nuray Bayraktar vd., Görsel Eğitimde Yaratıcıllk ve Temel Tasarım (Ankara: Nobel Yayınları, 2012), 14.

14 Nimet Kesen, Sanat Sözlüğü (Ankara: Nobel Yayınları, 2005), 237.

15 F. Ching, Mimarlık, Biçim, Mekân ve Düzen, çev. Gizem Aydın (Ankara: Nobel Yayınları 2002), 54.

16 Abdullah Demir, Temel Plastik Sanatlar Eğitimi (Eskişehir: Anadolu Üniversitesi Açı Öğretim Yayınları,1993), 8.

17 Serap Buyurgan ve Ufuk Buyurgan, Sanat Eğitimi ve Öğretimi (Ankara: Pegem Yayınları, 2012), 130.

18 Nevide Gökaydın, Temel Sanat Eğitimi (Ankara: Moss Eğitim, 2010), 72.

19 Meliha Yılmaz, Görsel Sanatlar Eğitiminde Uygulamalar (Ankara: Data Yayınları, 2010), 29.

20 Nimet Kesen, Sanat Sözlüğü (Ankara: Ütopya Yayınevi, 2009), 79.

21 Ching, Mimarlı, Biçim, Mekan ve Düzen, 12. 
Biçim, yüzey etkisi veren ve daha çok iki boyutlu iken form; üç boyutludur. Biçim; görsel olarak çizgi ile sınırlandırılmış veya renk ton gibi farklı değerlerle belirtilmiş bir alan olarak ifade edilirr ${ }^{22}$. Form ise; Iş1k-gölge, renk, anatomi, çizgi ve doku gibi elemanlarının hepsinin birden oluşturduğu görünüm; eserde yer alan bütün öğelerin birbirlerine bağlanıp örülerek meydana getirdikleri düzen olarak tanımlanır ${ }^{23}$. Biçim ve form arasında boşluk yer alır. Boşluklar aracılığı ile bir kompozisyonda en doğru etkiyi elde etmek mümkündür. Biçim ve form arasındaki birbirinin aynı boşluklar uygunluk ifade ederken, farklı boşluklar zıtlık ifadesi olarak karşımıza çıkmaktadır²4.

Yön, tasarımda biçimsel öğelerin yönü, sol-sağ, yukarı-aşağı ya da ileri-geri bakmasın1, doğrultusu ise daha çok yatay-düşey, çapraz olmasıyla ilgilidir ${ }^{25}$. Genel olarak üç esas yön vardır: Düşey, yatay ve diyagonal. Bir kompozisyonda genellikle yatay yönler edilgen, düşey yönler etken, diyagonal yönler ise hareketli ve dinamik bir etki yaparlar ${ }^{26}$.

Teknik olarak insan gözünün görebildiği 1şığın dalga boyudur. Renk güçlü bir görsel araçtır. Rengin temel bir dil olarak kullanıldığı her türlü çalışma ve üründe renk uyumu bir düzen hissi verir ve görsel bir merak uyandırır. Dolayısıyla renk seçimi ve renklerin bir araya gelişlerinde, renk sistemini ve rengin özelliklerini özetleyen renk çemberini bir rehber bilgi olarak özümsemek gerekir ${ }^{27}$. Bir kompozisyonda zıt renkler birlikte kullanıldığında birbirlerinin değerini arttırırlar. Komşu renkler birbirlerinin etkinliğini ve canlılığını azaltırlar. İki rengin farklı tonları yan yana gelirse, her iki rengin değeri artar. Açık renk daha açık, koyu renk daha koyu görünür ${ }^{28}$.

Doku, bir sanat eserinin yüzeyinin görünümü veya hissedilmesidir. Doğada var olan her şeyin yüzeyi kendi dokusu ile örtülüdür. Hem görme duyusuna hem de dokunma duyusuna hitap eden doku, nesnenin iç yapısı ve dış yapısı hakkında bilgi ve$\operatorname{rir}^{29}$. Görsel olarak algılanan dokular görsel doku, elle dokunulduğu zaman algılanan dokular ise dokunsal doku olarak adlandırılmaktadır.

\section{Yöntem}

$\mathrm{Bu}$ araştırma nitel bir araştırma olup araştırma verileri literatür tarama modeli kullanılarak elde edilmiştir. Tarama araştırmaları birçok farklı şekilde sınıflandırılabilmektedir. Karasar, tarama modellerini genel tarama modelleriyle örnek olay taramaları olarak ikiye ayırmaktadır. Genel tarama modelleri sadece bir değişkenin incelendiği

22 Gökaydın, Temel Sanat Ĕ̈itimi, 76.

23 Kesen, Sanat Sözlüğ̈̈̈,133.

24 Hulusi Güngör, Temel Tasar (İstanbul: Çeltüt Matbaası, 1972), 3.

25 Erol Turgut, Grafik Dil ve Anlatım Biçimleri (Ankara: Anı Yayıncılık, 2013), 150.

26 Güngör, Temel Tasar, 15.

27 Bayraktar vd, Görsel Eğitimde Yaratıclllk ve Temel Tasarım, 22

28 Hatice Aslan Odabaşı, Grafik'te Temel Tasarım (İstanbul: Yorum Sanat Yayınları, 2002), 84.

29 Keser, Sanat Sözlüğ̈̈, 104. 
ya da değişkenlerin tek tek incelendiği tekil tarama modelleriyle iki ya da daha çok sayıda değiş̧kenin aralarındaki ilişkilerinin de betimlenmek üzere incelendiği ilişkisel tarama modelleridir ${ }^{30}$.

Literatür taraması ise daha önce çalışılmamış, ihtiyaç duyulan ve özgün bir araştırma konusunun belirlenmesi, konu hakkında daha önce yaşanan tartışma ve gelişmelerin, temel kavram ve fikirlerin öğrenilmesi, araştırmanın gerekçesinin netleştirilerek araştırma soruları ve hipotezlerin oluşturulması, araştırma için uygun yöntemlerin belirlenmesi ve sonuçların bilime sağladığı katkıların tartışılması gibi amaçlarla gerçekleştirilmektedir. ${ }^{31}$

Çalışmanın amacı deneysel kolaj uygulamalarını tasarım elemanları ile ilişkilendirmek ve bu kapsamındaki deneysel çalışmaları tasarım elemanları bağlamında açıklamaktır. Bu amaçla "temel sanat eğitimi”" dersi için hazırlanan deneysel kolaj çalışmalarının öğrencilerin temel tasarım elemanlarını daha iyi öğrenebilmesi ve yaratıcı yönlerinin geliştirilmesi açısından faydalı olacağı düşünülmüştür. Temel Sanat Eğitimi dersi için tasarımı yapılan 47 adet deneysel kolaj çalışması arasından random (tesadüfi) olarak seçilen 10 adet deneysel kolaj çalışmasının eser analizleri temel tasarım elemanları açıklanmıştır.

\section{Bulgular ve Yorum}

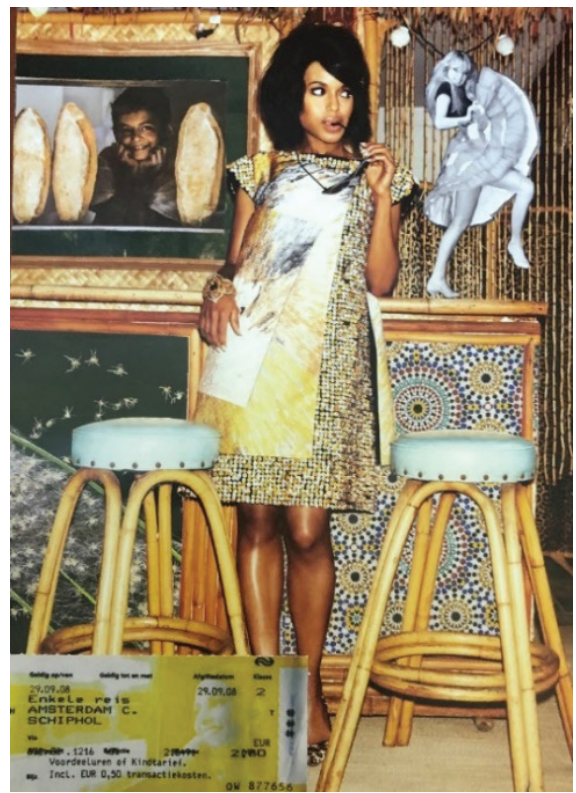

G. 2: Deneysel Kolaj Çalışması, 21,0 x 29,7 cm (Nurdan K. Şenol, 2020)

30 Niyazi Karasar, Bilimsel Araştırma Yöntemleri (Ankara: Nobel Yayınları, 2002), 89.

31 Yılmaz Arı ve İlhan Kaya, Coğrafya Araştırma Yöntemleri (Balıkesir: Coğrafyacılar Derneği Yayınları, 2014), 74 . 
Dadaizmde nesnelerin kendilerini temsil etmek isteyen anlayış kolaj üretiminde ve kolajın yapısal oluşumunda büyük bir etkendir. Modernizmle beraber gelen sanatta alternatif arayışlar nesne oluşturmak yerine daha kendiliğinden gelişen hazır nesneleri bir arada kullanmaya dönüşmüştür. G. 2. de olduğu gibi bir araya getirilen simetrik ya da asimetrik dengesel parçaların uyumu, anlatım ve ifadenin önüne geçmektedir. Ana unsur olarak ele alınan ortadaki kadın figürü, görsel açıdan tutarlı fakat içerik açısından alakasız birkaç yerleştirmenin arasında kalmaktadır. Zemine yerleştirilen simetrik figürlü op art yanılsamalı görsel, dikkat dağıtan rahatsız edici bir yapıdadır. Çalışma dikey tarzdadır. Ayaktaki kadın figürü ve arka plandaki çizgisel etki yaratan perde bu söylemi destekler niteliktedir. Genel olarak kolaj uygulamalarında derinlik hissini pek göremesek de bu görselde sol üst köşedeki eklenen parça, renk planı açısından bir derinlik hissi yaratmaktadır. Boyut etkisi ön- arka ilişkisi olarak ele alınmıştır. Ön plandaki yatay yönlü bilet görselinden bar taburelerine figürden duvara kadar derinlik birkaç katmandan oluşturulmuştur. Çalışmada, dikey bir yön hissi oluşturulsa da asıl yön hareketini figürün bakış yönü ve masanın üzerindeki dans eden kadın figürü vermektedir. Sarı ağırlıklı bir görselde hem derinlik oluşturmada hem de rengi dengelemek açısından kullanılan siyah beyaz parçalar izleyicinin gözünün çalışma üzerinde gezmesini sağlamaktadır.

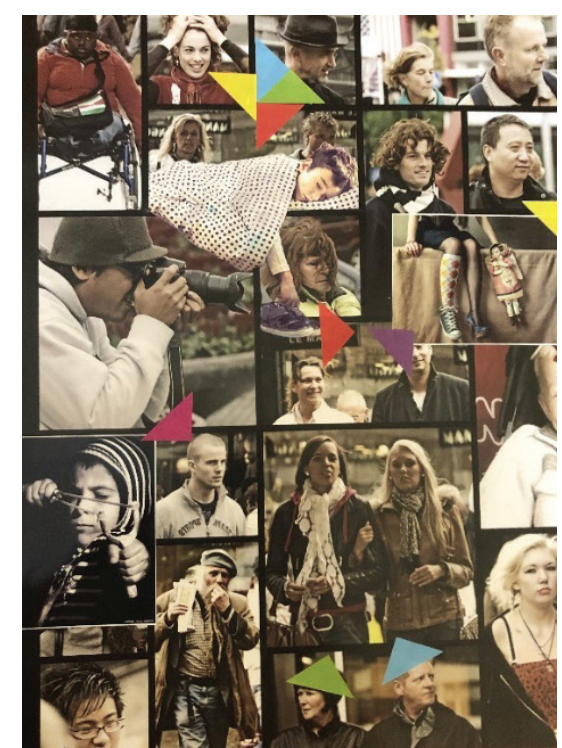

G. 3: Deneysel Kolaj Çalışması, 21,0 x 29,7 cm (A. Osman Elmas, 2020)

Kompozisyon oluşturmak için sanatçılar önceleri doğrudan doğayı ve insanı ele aldılar. Daha sonra farklı eserler vermek için canlı ya da ölü doğa nesnelerini ve çeşitli eşyaları kullanmışlardır. Fotoğrafın icadı ile artık sanatçı, doğrudan doğayı ve eşyayı izlemek zorunda kalmadan fotoğraf kareleriyle hiç gitmediği yerleri ve görmediği insanları resmetmeye başlamıştır. Fotoğraflar üzerinde oynanan çeşitli manipülasyonlar 
ile yeni grafiksel görüntüler oluşturulmuştur. Bir araya getirilen parçalar fotoğrafın dışında yeni bir anlatım formu oluşturarak absürt birleştirmeler ve kes-yapıştır ürünler ortaya çıkmaya başlamıştır. Bu da kolaj tekniğine görsel ve sanatsal açıdan birçok yenilik getirmiştir. G. 3'teki gibi hazır nesne olarak kullanılan fotoğraf kâğıdı üzerine, biçim olarak birbirini tamamlayan fakat büyük küçük uyumu ile de düzensiz bir yerleştirme yapılmıştır. Sepya ve kahverengi tonlar uyum içeresinde kullanılmıştır. Renk dengesi kolaj üzerine sonradan eklenen yapışkanlı not kağıtlarıyla sağlanmaya çalışılmıştır. Bir araya getirilmiş alakasız görseller karmaşa yaratmaktadır. Çalışma yönü eserdeki bakış yönü de olan sağ tarafa doğrudur. Boyut hissi pek oluşmasa da tek göze batan, çalışmanın sol üst kısmındaki uyuyan çocuk görselidir. Sanki kadrajdan sarkmışçasına bir izlenim vermektedir. Noktasal görünüm, hareket de katması için yine bu figürle yerleştirilmiştir. Bu görselde izleyiciye doğrudan bir karmaşa sunulmuştur.
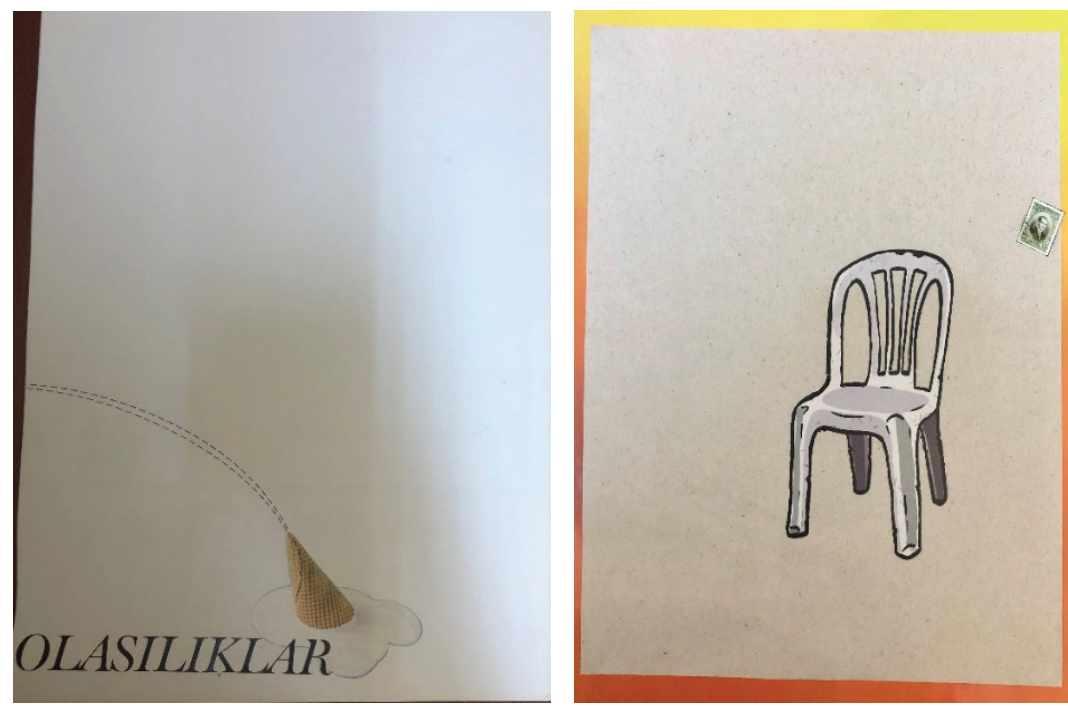

G. 4 ve G. 5: Deneysel Kolaj Çalışmaları 21,0 x 29,7 cm (A. Osman Elmas, 2020)

Temel özellikleri, izleyici ile eser arasında çarpışma yaratacak kadar yoğun bir etki sağlaması ve sanatı en uç sınırlarına kadar zorlaması olarak nitelendirilen minimal sanat; izleyiciye önemli sorumluluklar yükleyen bir akımdır. Diğer adı da yalın sanat olan minimalizm yeni bir akım olmasına karşı birçok sanat disiplinini etkilemeyi başarmıştır ${ }^{32}$. Maleviç, Duchamp ve Dadacılar akademizmin statükocu estetik beğenisini kırmak için kendilerini önceki bilgilerden soyutlamıştır. Nesneye dolaysız olarak şekil vermek yerine var olan bir nesneyi bağlamından ayrıştırarak onu bir sanat ürününe çevirmiştir. Amacı hem sanatçıya hem de izleyiciye güzelliğin iktidarını sorgulatmak-

32 Nurdan Kumaş Şenol, "Minimalist Sanat Akımının Moda Üzerindeki Etkisine Genel Bir Bakış”, Art Sanat 9 (2018), 437. 
tır. Bu fikirden yola çıkılarak oluşturulan G. 4. ve G. 5. doğrudan zemin görüntüsü üzerinde tek odakta ve en sade biçimde ifadesini gerçekleştirmektedir. G. 4'te beyaz fonun sonsuz derinliği üzerinde oluşturulan sahte düzlem, külah nesnesinin hacim ve dokusu görseli güçlendiren en temel iki unsurdur. G. 5'te ise saman kâğı̀ının dokusu ve onun çevresini sınırlayan, renkli bir paspartu kullanılmıştır. Kosuth'a bir gönderme niteliğindeki bu çalışma "Bir sandalye üç sandalye" işindeki fikir gibi nesnenin estetik değerini dışlayarak onun aracı olduğu kavramsal bir bütünü absürt bir şekilde ortaya koymaktadır. Saman kâğıdının ucuz ve basit görüntüsü ve sandalyenin karikatür çizimi bu görüngüyü vurgulaması açısından kullanılmıştır. Çizgisel değerler konturla, renk paspartuyla, yön ve hacim figürle oluşturulmuştur. Asimetrik konumlandirılan pul görseli, etrafındaki noktalar ve deseniyle çalışmayı tekdüze olmaktan kurtarmış hareket kazandırmıştır. G. 4'te çocukluğun saklı dolabından çıkarak önümüze gelen dondurma düşürme korkusu, doğrudan ve en alaycı şekilde vurgulanmıştır. Soldan sağa düşüş çizgisi çalışmaya hem yön vermiş hem de kullanılan çizgi renkleriyle dondurma gerçekliğini soğuktan sıcağa doğru iletmiştir. Kullanılan tipoğrafik parça zaten üç boyutlu görselin önünde kalarak çalışmada derinliğin yanı sıra zemin hissiyatını da desteklemektedir. Yazının içeriği ise hicivle anlatılan görseli destekler niteliktedir. Külahın dokusu odağı doğrudan kendi üzerine almaktadır. Analizi yapılan iki çalışmada da az biçim ile çok anlatım fikri doğrudan uygulanmıştır.

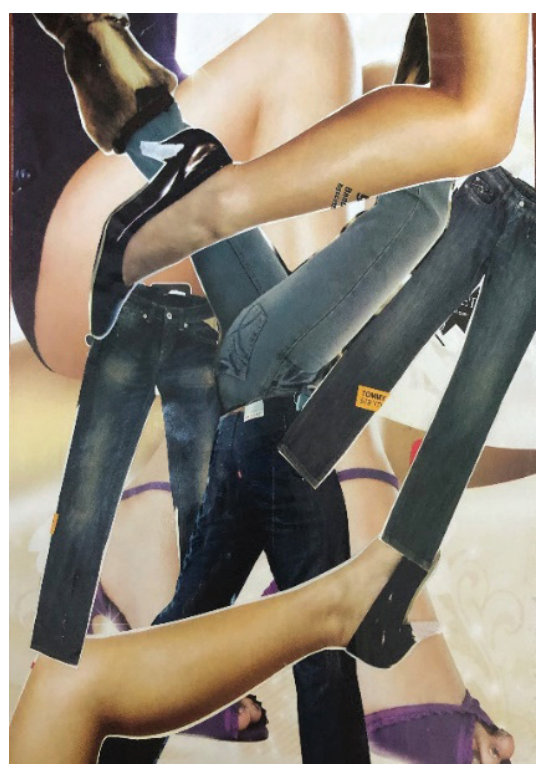

G. 6: Deneysel Kolaj Çalışması, 21,0 x 29,7 cm (A. Osman Elmas, 2019)

Kıyafetler, renkler, kadın figürleri ve ilginç kolajlarıyla Pop art; sanat ve moda alanında farklı bir bakış açısı oluşturmuştur. G. 6 buna benzer teşkil eden bir örnektir. Nesnelerin kendi işlevlerinin dişında birbirleri ile ilişkilendirilerek oluşturulan bu 
çalışma 1960'lar pop art stilini yansıtmaktadır. Görselin zeminini oluşturan ve tüm arka plana yayılan bir manken figürü bulunmaktadır. Üst üste gelen katmanlar ve koyu renk hâkimiyetini rahatlatan açık tonda zemin rengi görsele derinlik ve rahatlık hissi vermektedir. Orta alanda bulunan ters konumlandırılmış iki kot pantolon görseli resmin köşelerine doğru bir yol izlemekte ve odağı orta alana toplamaktadır. Çalışmada yön kavramı karmaşık bir şekildedir. Her parça kendi içinde bir yön ve hareket sağlamaktadır. Noktasal öğeler bulunmayan görselde çizgisel ve lekesel parçalar ön plandadır. Çizgiler kot dikişleri ve kolaj parçalarının kenar kesiklerinde görülmektedir. Açık ve koyu oranı doğru bir şekilde kullanılmıştır. Derinlik hissini sağlayan katmanlar sahte bir espas oluşturmaktadır. Boyut ve form, kolaj üzerinde kullanılan parçaların fotoğrafik görselleriyle meydana getirilmiştir.

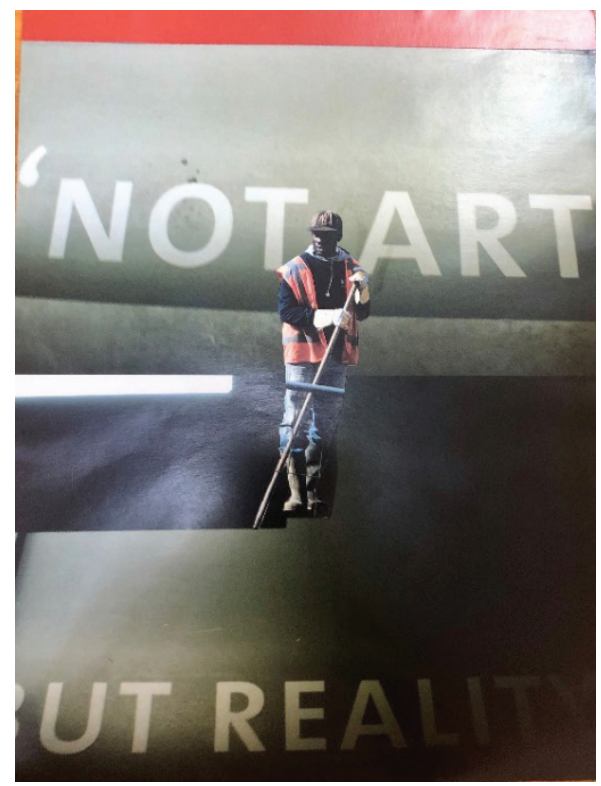

G. 7: Deneysel Kolaj Çalışması, 21,0 x 29,7 cm (A. Osman Elmas, 2019)

Hazır arka plan ve fotoğrafların zemin olarak kullanıldığı kolaj yüzeyler bu çalışmada da karşımıza doğrudan çıkmaktadır. Tek görsel üzerine uygulanan manipülasyonla çalışmanın odağına elinde sopa/fırça olan bir belediye işçisi konumlandırılmıştır. Sepya tonlar zeminde ağırlıklı kullanılmıştır. Görseli doğrudan enine bölen üç tane çizgisel parça bulunmaktadır. G. 7 net açık ve net koyu tonu olmayan bir zemine sahip olduğu için vurgu, üzerine 1şık yansıyan merkez obje ve kolajı tepeden kesen kırmızı bantla oluşturulmuştur. Tipoğrafik öğeler görsele hareket kazandırmış ve kolajın yatay yönlü hareketini desteklemiştir. Dokusal olarak ortada yer alan figürün kendisi ve kıyafetlerinin doku meydana getirdiği bu görselde derinlik hissi oluşturulmamıştır. Zeminde kullanılan yazı, merkeze yerleştirilen figürle ekspresyonist bir ifadeyi sağlamıştır. Doku ve nokta yerine çizgisel ve lekesel değerlere yer verilmiştir. 

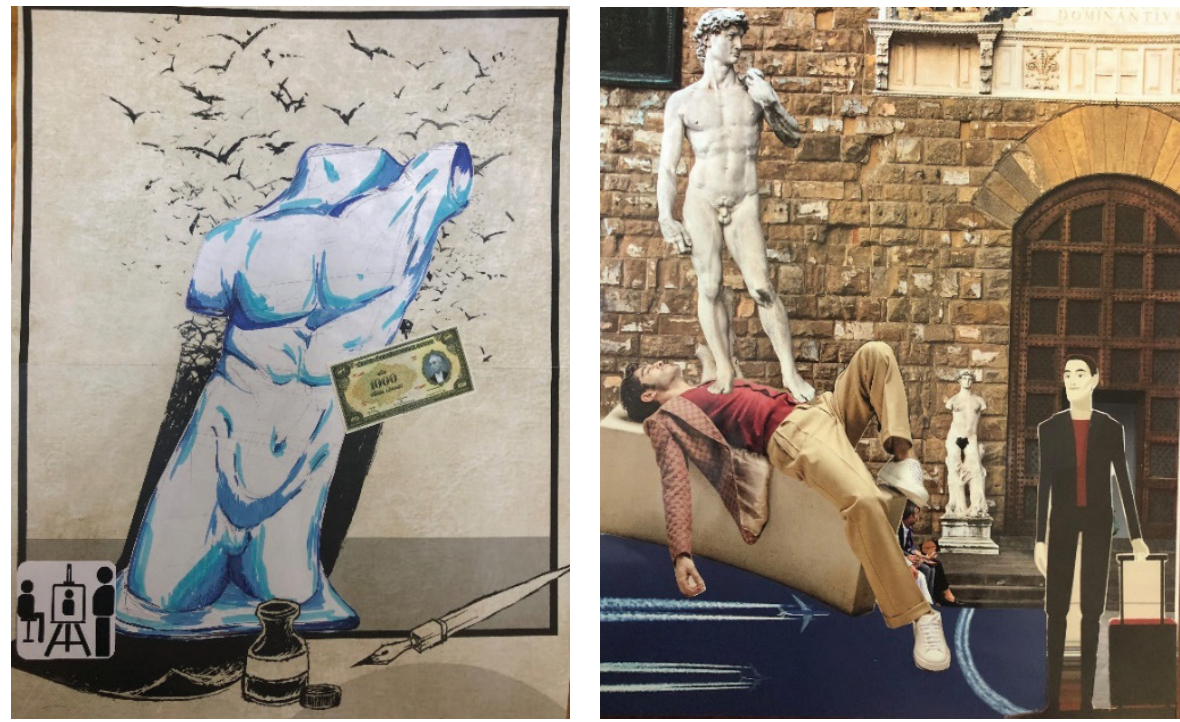

G. 8 ve G. 9: Deneysel Kolaj Çalışmaları, 21,0 x 29,7 cm (Nurdan K. Şenol, 2020)

Modernizmle birlikte sanat alanındaki değişim ve arayış Dada, Süprematizm, Pop art ve Op art'ta savaş sonrasında kendini yoğun şekilde göstermeye başlamıştır. Eser üretimindeki alışılagelmiş tekniği bir kenara bırakan sanatçılar bazen geçmişin objelerini yeniyle, bazen de yeniden obje üretimiyle farklı varyasyonlar ve biçemler ortaya çıkarmışlardır. Asıl olanın fikir olduğunu eserlerinde gösteren sanatçılar plastik sorunlardan düşünsel sorunlara yönelmişlerdir. Artık eserler hazır nesnelerle ya da iyi düşünülmüş ve bir araya getirilmiş kompozisyonlarla ortaya çıkmaya başlamıştır. Nesne odaklı kompozisyonlarda yer yer geçmişten izler, Ortaçağ resimlerindeki dinsel temalar ve planlar kullanılmıştır. G. 8. ve G. 9. bu fikirle oluşturulan iki çalışmadır. G. 8'de eser odağı zemin lekesine uygun konumlanan renkli kalem tors çizimi ile sağlanmıştır. Soluk zemin rengi ve degrade dokusu arka planda bir duvar izlenimi yaratmaktadır. Nokta, çizgi ve lekesel değerler dıştan içe çalışmanın ritim ve hareketini sağlamaktadır. Çalışma açık kompozisyondur. İç çerçeveden taşan torsa, kâğıt, hokka ve divit ön arka ilişkisi oluşturarak esere derinlik sağlamıştır. Açık ve koyu mavi tonlar ile ön plandaki siyah beyaz piktogram görseli çalışmanın koyu ve gri havasına ferahlık kazandırmıştır. Çalışmada yön hissi yoktur fakat sağ alttan sol üste doğru diyagonal bir yerleşim planı göze çapmaktadır. Dikey çalışılan görsel üzerinde kullanılan parçalar asimetrik yerleştirilmiş ve zemin mekân bütünlüğü sağlanmıştır. Aynı şekilde $\mathbf{G . ~} 9$ bir bina görseli önünde konumlandırılan beş figürle desteklenmiştir. Mekân bütünlüğü görselin tematik yapısı ile sağlanmıştır. Duvardaki taş dokusu zemine hem ritmik bir hareket hem de güçlü bir efekt vermiştir. Sağ alt plandaki grafiksel figür sanat gezgini edasında müze önünde ve görselin en dışında konumlandırılmıştır. Kapalı formdaki bu çalışma alt tarafta bulunan gökyüzü görseliyle rahatlatılmaya çalışılmıştır. Sol üst bölümde bulunan Davut heykeli aşağı tarafa doğru hareket eden 
bir figürün üzerinde kayak yaparcasına konum almıştır. Çalışmada yatay ve dikey çizgiler orantılı kullanılmıştır. Zemindeki duvar ve kapı detayları noktasal ve dokusal etkiler yaratmıştır. Çalışma yönü sol üstten sağ alta doğru diyagonal şekilde inmektedir. Kırmızı kahverengi ve mavi tonlarının yanında açık koyu dengesiyle de çalışma uyum içindedir.

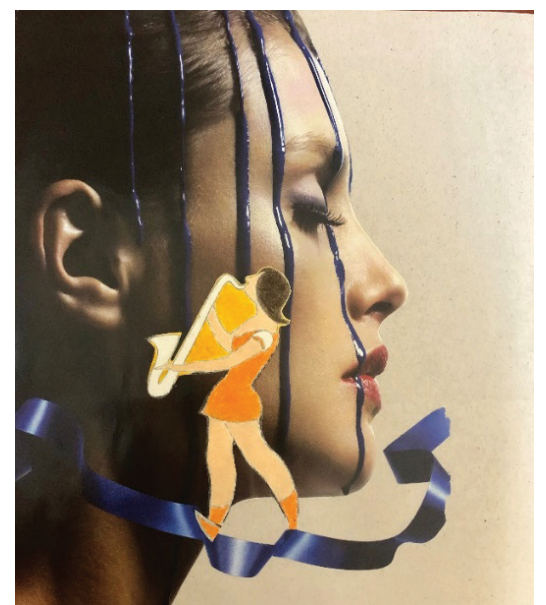

G. 10: Deneysel Kolaj Çalışması, 21,0 x 29,7 cm (A. Osman Elmas, 2019)

G.10. temel kolaj mantığının basit bir şekilde ele alındığı bir çalışmadır. Yüzün formu ve boyutu açıkça hissedildiğinden zeminde bu görüntüyü vurgulamak açısından beyaz yerine Kraft kâğıdı kullanılmıştır. Soldan sağa doğru koyudan açığa dengeli bir ton geçişi bulunmaktadır. Mor sarı ve turuncu renk sıcak soğuk dengesi sağlarken kontrast oluşturmuş, aynı zamanda görsele vuran 1şık etkisini güçlendirmiştir. Ten dokusu detaylı bir şekilde izlenmektedir. Noktasal ve çizgisel değerlerin kullanılmadığı bu görselde renk ve hacim ön plandadır. Çalışmanın en üst ve orta kısmında yer alan figür ters yöne duruşuyla denge unsuru oluşturmuş̧tur. Çalışma yönü soldan sağa doğru izlenmektedir.

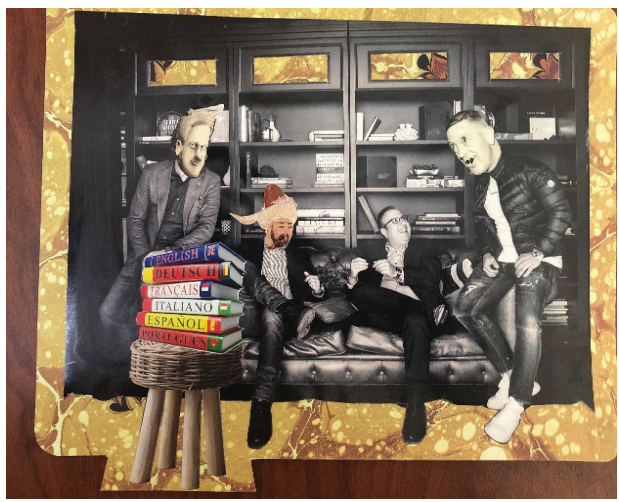

G. 11: Deneysel Kolaj Çalışması, 21,0 x 29,7 cm (A. Osman Elmas, 2020) 
Foto-manipülasyon sayılabilecek G.11'de pop art kolaj işlerinin genelinde kullanılan esprili bir anlatım vardır. Siyah beyaz bu çalışmada kasvetli havayı kırmak için arka plandaki çerçeveler içine yer yer boşluklar açılarak zemine konumlandırılmış olan ebru deseninin ortaya çıkması sağlanmıştır. Çalışma açık kompozisyondur. Çerçeveden taşan figürlerin ayakları ve ön planda duran sehpa ön arka ilişkisinin yanında derinlik de sağlamaktadır. İlginç tiplemelerin ve figürlerin bazılarının baş kısmına yerleştirilmesiyle absürt bir hava oluşturulmuş, bakışların alakasız duruşu ile de Rembrandt'1n "Dr. Nicolaes Tulp'un Anatomi Dersi”, eserine bir öykünme yapılmıştır. Çağdaş anlayışla öykünme, kopya etme sürecinden ziyade sanatçının üslubunun ya da öykünerek oluşturduğu eserin kendi olma özelliklerinin daha üstün ola durumudur. Sanatçılar genellikle kendilerinden öncekilere öykünerek kendi yaratıc1lıkları doğrultusunda sanatsal gelişimlerini şekillendirmişlerdir ${ }^{33}$.

Çalışmanın zemininde kullanıla kitaplıkta dikey ve yatay çizgiler vurgulanmıştır. Aynı zamanda zemindeki ebru deseninde noktasal, gelişigüzel atılmış lekeler bulunmaktadır. Bu lekeler çalışmaya hareket kazandırmıştır. Eserin sol alt bölümünde sehpa üzerinde duran kitap görseli renk açısından en göze batan nesnedir.

\section{Sonuç}

Kolaj tekniğinin uygulama alanları 20. yüzyılda dönemin hızla gelişen endüstrileşmesinden nasibini alarak farklı formlara evrilmiştir. Bu yeni sanat anlayışından etkilenen birçok sanatçı alışılagelmişin dışında çalışmalar üretmişlerdir. Özellikle bu fikri ortaya çıkaran kübistler ve dadaistlerin fikirleri bu çalışmada da ön planda olmuştur. Kolaj; sanatsal uygulamalar üzerindeki kurgusal çeşitliliğe hızlı çözümler sunarak, sanatçının yaratma güdüsünü zengin anlatımlarla çoğaltııştır. Bu zengin anlatımı nitelik olarak da besleyen belli başlı unsurlar vardır. Bunların en temelini de tasarım elemanları oluşturmaktadır.

Bu çalışmada temel tasarım elemanları ile kolaj uygulamalarının arasındaki ilişkinin tespit edilmesi ve yaratım süreci ve öğrenme kabiliyetinin görsel anlatım ile zenginleştirilmesi amaçlanmıştır. Bu amaç doğrultusunda incelenen akademik çalışmalar, üretilen deneysel işlere emsal teşkil etmiştir. Anlatım ve ifade açısından tekniğin, temel tasarım öğelerinin kavranmasında faydalı olacağı öngörülmüştür.

İki eğitimcinin çalışmalarından random (rasgele) olarak seçilen 10 adet deneysel kolaj çalışması; temel tasarım elemanları dikkate alınarak yorumlanmıştır. Yorumlanan tasarım elemanlarından hemen hemen hepsinde bulunan derinlik, denge ve çizgi elemanlarının özgünlüğü arttırmaya daha çok katkı sağladığı düşünülmüş; yön elemanı ise çalışmada en az tekrarlanan öğe olarak belirlenmiştir.

33 Figen Girgin, Çăgdaş Sanat ve Yeniden Üretim (İstanbul: Hayalperest Yayınları, 2018), 39. 
Elde edilen çözümlemeye göre tasarımcıların bakış açısını genişleten bu sanat dalının kendine has yorumlama gücü yapılan tasarımların değerini ve özgünlüğünü daha da arttıracağı sonucuna varılmıştır.

Hakem Değerlendirmesi: Dış bağımsız.

Çıkar Çatışması: Yazarlar çıkar çatışması bildirmemiştir.

Finansal Destek: Yazarlar bu çalışma için finansal destek almadığını beyan etmiştir.

Peer-review: Externally peer-reviewed.

Conflict of Interest: The authors have no conflict of interest to declare.

Grant Support: The authors declared that this study has received no financial support.

\section{Kaynakça/References}

Acar, Sedef. “Jack Lenor Larsen: İç Mekân Tekstili Tasarımında Bir Öncü” İnönü Üniversitesi Sanat ve Tasarım Dergisi 7 (2013): 81-91.

Arı, Yılmaz ve İlhan Kaya. Coğrafya Araştırma Yöntemleri. Balıkesir: Coğrafyacılar Derneği Yayınları, 2014.

Bayraktar, Nuray, Nilgün Görür Temel ve Ayşe Tekel vd. Görsel Eğitimde Yaratıcılık ve Temel Tasarım. Ankara: Nobel Yayınları, 2012.

Beyoğlu, Aylin. "Sanat Eğitiminde Kolaj Tekniği ve Richard Hamilton'ın Eser Örneğinin İncelenmesi”. Ege Eğitim Dergisi 16 (2015): 225- 241.

Buyurgan, Serap ve Ufuk Buyurgan. Sanat Ĕgitimi ve Öğretimi. Ankara: Pegem Akademi, 2012.

Ching, Francis. Mimarlık, Biçim, Mekan ve Düzen. Çev. Gizem Aydın, Ankara: Nobel Yayınları, 2002.

Demir, Abdullah. Temel Plastik Sanatlar Eğitimi. Eskişehir: Anadolu Üniversitesi Açık Öğretim Yayınları, 1993.

Durak, Mustafa. Kolaj Tarihine Giriş. Erişim 24 Nisan 2020, https://tr.scribd.com/ document/23283244/kolaj-tarihinegiriş-

Ergün, Cemil. “Temel Sanat Eğitiminde ve Çağdaş Sanatta Kolaj- Fotomontaj”. Sanat ve Tasarım Dergisi 1 (2014): 5-19.

Fox, Englebright Jill and Robert Schırrmacher. Çocuklarda Sanat ve Yaratıcılığın Gelişimi. Çev.

Neriman Aral ve Gökhan Duman. Ankara: Nobel Yayınları, 2012.

Girgin, Figen. Çăgdaş Sanat ve Yeniden Üretim. İstanbul: Hayalperest Yayınları, 2018.

Gökaydın, Nevide. Temel Sanat Eğitimi. Ankara: Moss Eğitim, 2010.

Güngör, Hulusi. “Temel Tasar”. İstanbul: Çeltüt Matbaası, 1972.

Hamilton, Richard. Kolaj. İstanbul: Boyut Yayın Grubu, 2013.

Karakaya, Betül ve Menekşe Ela Öztürmen. "Porselen bibloda Kolaj ve Asamblaj”. International Journal of Interdisciplinary and Intercultural Art 9 (2019): 23-37.

Karasar, Niyazi. Bilimsel Araştırma Yöntemleri. Ankara: Nobel Yayınları, 2004.

Kesen, Nimet. Sanat Sözlüğ̈̈. Ankara: Ütopya Yayınevi, 2005.

Kılıç, Kardelen. “2000’li yıllarda Türkiye'de Kolaj: Sanatçılar ve Uygulamaları”. Yüksek Lisans Tezi, Uludağ Üniversitesi, 2019. 
Krausse, Anna- Carola. Rönesans 'tan Günümüze Resim Sanatının Öyküsü. Çev. Dilek Zaptcığlu, İstanbul: Literatür Yayıncılık, 2005.

Kumaş Şenol, Nurdan. "Minimalist Sanat Akımının Moda Üzerindeki Etkisine Genel Bir Bakış". Art-Sanat 9 (2018): 437-448.

Lynton, Norbert. Modern Sanatın Öyküsü. Çev. Cevat Çapan ve Sadi Öziş, İstanbul: Remzi Kitabevi 2004.

Odabaşı, Hatice. Grafik'te Temel Tasarım. İstanbul: Yorum Sanat Yayınları, 2002.

Sözen, Metin ve Uğur Tanyeli. Sanat ve Terimleri Sözlüğü. İstanbul: Remzi Kitabevi, 2005.

Turani, Adnan. Dünya Sanat Tarihi. İstanbul: Remzi Kitabevi, 1995.

Turgut, Erol. Grafik Dil ve Anlatım Biçimleri. Ankara: Anı Yayıncılık, 2013.

Yılmaz, Meliha. Görsel Sanatlar Eğitiminde Uygulamalar. Ankara: Data Yayınları, 2010. 
